\title{
Determinants of Growth in Multiunit Housing Demand since the Great Recession: An Age-Period-Cohort Analysis
}

\author{
Shiv N. Mehrotra' ${ }^{1}$ and Douglas R. Carter $^{2}$ \\ ${ }^{1}$ Faculty of Forestry, University of Toronto, 33 Willcocks Street, Toronto, ON, Canada M5S 3B3 \\ ${ }^{2}$ School of Forest Resources and Conservation, University of Florida, 357 Newins-Ziegler Hall, Gainesville, FL 32611, USA \\ Correspondence should be addressed to Shiv N. Mehrotra; shiv.mehrotra@gmail.com
}

Received 17 June 2017; Accepted 28 August 2017; Published 12 October 2017

Academic Editor: Thomas Panagopoulos

Copyright (c) 2017 Shiv N. Mehrotra and Douglas R. Carter. This is an open access article distributed under the Creative Commons Attribution License, which permits unrestricted use, distribution, and reproduction in any medium, provided the original work is properly cited.

\begin{abstract}
Following the Great Recession (2007-2009), growth in multiunit housing starts has been exceptionally strong and sustained. In this study, we examine empirical evidence for three possible explanations, namely, the passage of Baby Boomers into senior years, the depressed economic conditions, and rising preference of recent birth cohorts for residing in urban cores. Applying Age-PeriodCohort analysis to census data on multiunit housing occupancy from 1970 to 2010, we find evidence to support the explanations that a sharp increase in demand from Millennials drawn to urban cores and retiring Baby Boomers are contributing to the growth in multiunit housing starts. The results provide weak evidence of a negative relationship between depressed economic conditions and demand for multiunit housing starts. Over the long term, demand for multiunit housing can be expected to moderate as a result of the projected aging of the population.
\end{abstract}

\section{Introduction}

Growth in multiunit housing starts has been strong and sustained since the end of the Great Recession (lasting from November 2007 to June 2009). While multiunit (defined as housing structures with 5 or more units) housing starts have exceeded their pre-Great Recession peak, single-unit housing starts have yet to reach their pre-Great recession peak or their long-term trend level (Figure 1).

Typically, multiunit housing is offered in congested localities, where demand for housing far exceeds the land available for it. In comparison to single-unit housing in the locality, multiunit housing provides a smaller living space at an affordable cost, requiring lower housing maintenance. It also offers proximity to locations visited frequently for work or nonwork related activities (shopping, education, recreation, etc.), reducing the cost of and time expended in commuting.

Rappaport [1] identifies two explanations for the growth in post-Great Recession multiunit housing starts. The first is the aging of the early Baby Boomer generation into retirement resulting in an increase in trading-in of larger single-unit housing in favor of affordable and smaller single and multiunit housing. The second is the economic stress created by the recession, a slow recovery, and tepid wage growth that are resulting in postponement of investment in single-unit housing and increase in demand for multiunit housing.

Research on the housing life cycle highlights the influence of life stage on the choice of housing structure (Clark and Dieleman [2]). A birth cohort (defined as a group of people that share a common birth period) begins to form independent households in its late teens to early 20 s, typically starting with renter households (all subsequent use of the term cohort in this study refers to a birth cohort). The cohort begins transitioning to larger houses and owner occupancy starting in its late 20 s as family size grows. In its senior years, reduced space requirement and the need to close the incomeconsumption gap result in downsizing of housing (Jones [3], VanderHart [4]).

"Baby Boomers" describes persons born immediately following World War II, approximately between the years 


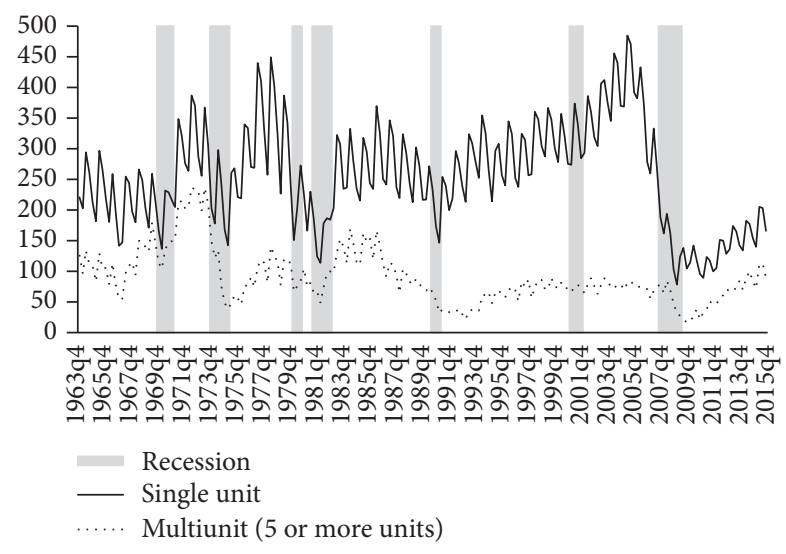

FIGURE 1: Economic recessions and housing starts: 1963Q4-2016Q2 (source: National Bureau of Economic Research [29] and Census Bureau [10]).

1946 and 1964. During this period the birth rate remained consistently above 20 births per thousand population, averaging 24.25 births, creating a "baby boom." In contrast, the birth rate for the preceding Silent Generation (1928-1945) averaged 20, while for the succeeding Generation X (1965-1980) it averaged 16.4. As a result, the Baby Boomer generation is distinguished by its size and its ability to move markets on account of it. Early Baby Boomers reached age 65, considered the dividing point between working-age adults and "seniors," in 2011 (Myers and Ryu [5]). Late Baby Boomers will reach this threshold in 2029. With the passage of the cohort into the retirement phase of life, it is anticipated that they will significantly impact the markets for single and multiunit housing as they trade large single-unit houses for smaller single and multiunit housing.

The Great Recession was preceded by a proliferation of subprime housing mortgage loans. Substantial defaults in the housing mortgage market resulted in collapse of the US housing construction industry during the recession. The post-recession period has been characterized by tightening of credit supply to the housing sector. At the same time, while the broader economic recovery from the recession has been slow, monetary policies adopted to stimulate the recovery are believed to have caused a speculative rise in asset prices. In particular, while house prices have recovered to pre-recession levels in many regions, real wages have been stagnant, reducing housing affordability. The S\&P/CaseShiller 20-City Composite Home Price Index (source: Federal Reserve Bank of St. Louis [6]) has risen from 142 in July 2009 to 187 in July 2016. Median weekly real earnings (unadjusted) for full-time employed workers reported by the Bureau of Labor Statistics [7] have changed from \$342 in the third quarter of 2009 to $\$ 343$ in the second quarter of 2016 (1982-1984 CPI Adjusted Dollars). The composite Housing Affordability Index published by the National Association of Realtors (source: Federal Reserve Bank of St. Louis [6]) has declined from over 200 post-recession to 156 in July 2016. The National Association of Home Builders/Wells Fargo Housing Opportunity Index (source: National Association of Home Builders [8]) declined from 70 in third quarter of 2009 to 62 in second quarter of 2016. These economic conditions are likely responsible in part for the post-recession rise in demand for multiunit housing. Rappaport [1] argues that large portions of the population that are still recovering from the economic shock of the Great Recession are fueling demand for the relatively affordable multiunit housing over single-unit housing, to rent or own.

A third possible explanation for growth in post-Great Recession multiunit housing starts is suggested by observations on recent trends in urbanization in Frey [9]. After doubling over the last century (from $39.6 \%$ of the total population in 1900 to $79 \%$ in 2000 ), the urban population rose from $80.7 \%$ in 2010 to an estimated $85.6 \%$ in 2015 (Census Bureau [10]). Based on analysis of Census Bureau data, Frey [9] reports that between 2010 and 2015 the annual growth rate of cities with population over 50,000 was double the average annual rate between 2000 and 2010. After 2010, the combined populations of the largest cities grew more than one percent a year, compared with only 0.5 percent, on average, during the 2000 to 2010 period. Most significantly, while the majority of past urban growth took place in the suburbs, from 2010 this trend was reversed and the growth rate of urban cores of the nation's major metropolitan areas was faster than their surrounding suburbs. Studies like Glaeser and Saiz [11], Moretti [12], Diamond [13], and Couture and Handbury [14] have also examined the trend of young, college educated professionals settling in select urban centers since the 1980s, contributing to high growth rate of the cities. Population growth in dense urban cores should translate into significantly higher demand for multiunit housing.

Reviews of literature on multiunit housing by Jud et al. [15] and Zietz [16] reveal that the impact of demographics, economic cycle, or urbanization on demand has been largely overlooked. Research on the link between housing demand and economic cycles, while extensive, is primarily devoted to investigating the impact of housing investments on business cycles (e.g., Zarnowitz [17]). Research on the impact of Baby Boomers generation on the housing market is largely concerned with single-unit housing (e.g., Mankiw and Weil [18], Hamilton [19]). While the impact of trends in urbanization on housing demand has been examined by studies like Masnick [20], they do not focus on multiunit housing. Pertinent to the present study, Rappaport [1] utilizes housing occupancy data to examine the rising demand for multiunit housing after the Great Recession. The study argues that the rise in demand can be attributed to delayed family formation by Millennials (1981-1997 birth cohort) suffering from the depressed economy, as well as Baby Boomers downsizing housing as they reach senior years.

In this study, we use historical data on occupancy to find empirical evidence for impact of housing life cycle, economic cycles, and population growth in urban cores on the choice of multiunit housing. While there are several factors that impact housing choice, this study focuses on these three variables to explain the exceptional growth in postGreat Recession multiunit housing starts. Using Age-PeriodCohort analysis, we find statistically significant evidence for two of the three explanatory variables. The results of the 
analysis confirm the housing life cycle theory, supporting the explanation that demand from retiring Baby Boomers may be contributing to rise in multiunit housing investments. The evidence also supports the explanation that population growth in urban cores has been contributing to growth in multiunit housing demand since the arrival of Generation X in the housing market in the 1980s, with demand from the succeeding Millennials generation rising sharply. The results provide weak evidence of a negative relationship between economic cycles and multiunit housing demand.

Section 2 discusses the three determinants of multiunit housing demand. Section 3 describes the data utilized and the methodology of Age-Period-Cohort analysis. Section 4 presents the results of the analysis. Section 5 discusses the results and conclusions.

\section{The Determinants of Growth in Multiunit Housing Demand}

Lansing and Kish [21] propose 9 stages in a typical family life cycle, to be used as a demographic independent variable capturing the changes in individual attitudes and preferences as they age. Adapting for the multiunit housing market, the 4 stages in the life cycle begin when a young unmarried individual leaves the parental home to form a separate household, alone or with friends (McCarthy [22]). In this stage, the individual establishes economic independence through regular full-time employment, though income is relatively low. In the second stage, the individual marries to form an independent household as a young couple. Household income increases from the combined contributions of the couple. The third stage commences with addition of children to the household. Household income continues to increase commensurate with acquisition of occupational skills and seniority, as well as earnings of adolescent children. In the last stage, the grown-up children have departed the household, leaving behind an older couple or individual. Household income drops as the couple or individual retires from the labor force. In this manner, the age dependent four stages of the housing life cycle capture the impact of housing choice determinants like marital status, family size, labor force participation, and current and expected future income and assets (Pitkin and Masnick [23]).

McCarthy [22] finds that few young single householders own their home. Most rent their homes and a majority of these renters live in apartments, consistent with their relatively small space requirements, lower incomes, and significant occupational instability. The 2009 American Housing Survey (Census Bureau [10]) reports that $86 \%$ of units in multifamily structures are rented, while $87 \%$ of single-family housing is owner-occupied. House ownership and a shift to single-unit housing take off as individuals marry, reflecting the higher household income and space requirement, though a significant move occurs when children join the household. In the last stage of the life cycle, after the children have left home and household income is reduced following retirement from the labor force, demand for large single-family units declines in favor of smaller single-family units and apartments.

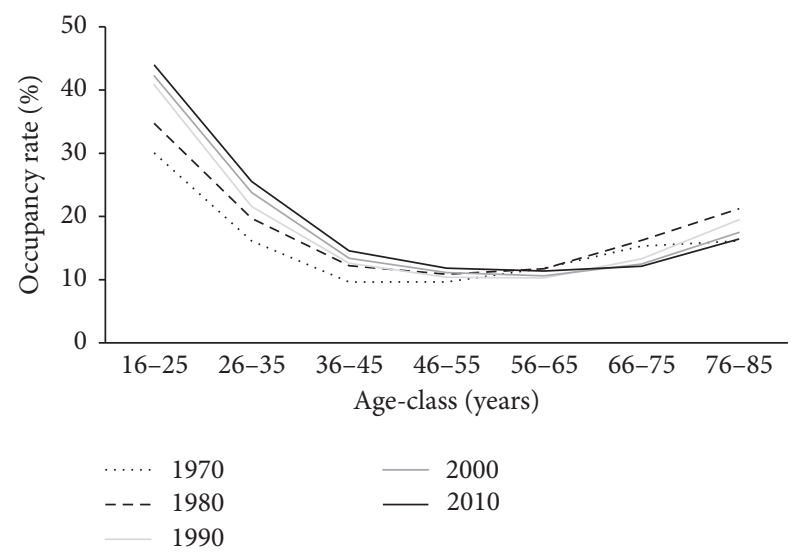

FIGURE 2: Rates of multiunit housing occupancy over age of householders: 1970 to 2010 census (source: Ruggles et al. [24]).

Figure 2 plots the rate of multiunit housing occupancy over age of householders, recorded in decennial census (Ruggles et al. [24]) from 1970 to 2010. The rate of multiunit housing occupancy is calculated as the percentage of total householder population in an age-class that resides in multiunit housing. In every census it is observed that the rate of multiunit housing occupancy is the highest (ranging from 30 to $45 \%$ ) in the 16-25 years age-class. Occupancy rate falls sharply to the $15-25 \%$ range for the $26-35$ years age-class and further to the $10-15 \%$ range for the 36-45 years age-class. Occupancy rate is relatively stable in the $10-15 \%$ range for the 46-55 and 55-65 years age-classes. Occupancy rate rises to the 15-20\% range for the 66-75 and 76-85 years age-classes. The rising trend in occupancy rate over successive census in the youngest age-classes could reflect their rising preference for residing in urban cores, as discussed later. It may also reflect trends like rising age of marriage and child bearing (Kreider and Ellis [25]). The falling trend in occupancy over successive census in the oldest age-classes may be a reflection of repelling factors like rising congestion, crime, and racial diversity of cities (Katzman [26], Frey [27]). Overall, the data appears to support the housing life cycle theory.

During an economic recession large sections of the population suffer from unemployment and reduced incomes. The demographic impacted the most by economic recessions is the youngest working-age population (Bureau of Labor Statistics [7]), a large section of which does not own houses. The recessionary conditions impact the ability of this section of the population to make sizeable investments in house ownership, resulting in postponement of the decision. As a result, the demand for rental multiunit housing can increase. The magnitude of the increase in demand for multiunit housing can be expected to depend on the magnitude and duration of depressed economic conditions. Figure 3 graphs multiunit occupancy rate for each decennial census from 1970 to 2010, for different age-classes. The shaded bars represent periods of recession (source: The National Bureau of Economic Research [28]). The 1970, 1980, and 1990 censuses were coincident with recession years. The recessions lasted from December 1969 to November 1970, January 1980 to July 1980, 


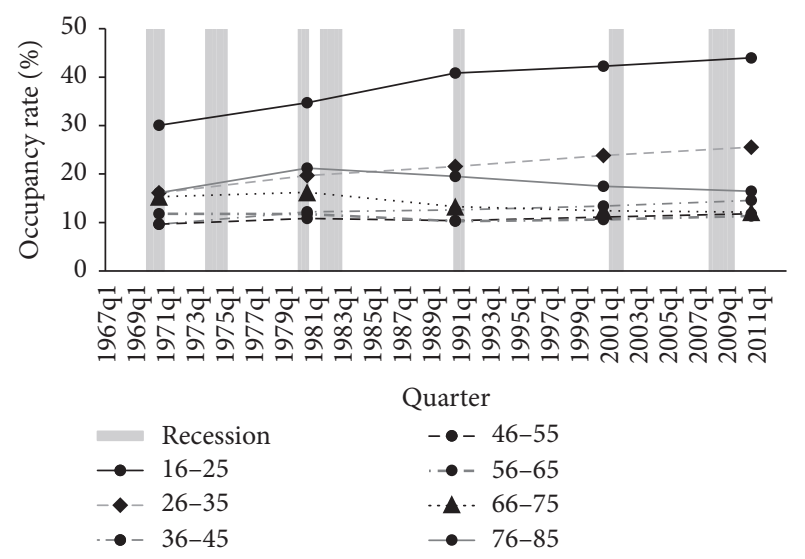

FIGURE 3: Rates of multiunit housing occupancy from 1970 to 2010: for different age-classes (source: Ruggles et al. [24] and The National Bureau of Economic Research [28]).

and July 1990 to March 1991. The 2000 and 2010 censuses were held in periods of economic growth. The line plots do not display any uniform trend over age.

Many variables impact housing choice over time. Government policy interventions in the housing market (e.g., Fair Housing Law of 1988, Multifamily Assisted Housing Reform, and Affordability Act of 1997) impact multiunit housing occupancy rates. As discussed earlier, the rising trend in occupancy rate for the 16-25 and 26-35 years age-classes could be a reflection of trends like rising age of marriage and child bearing. The falling trend in occupancy rate of the senior age-classes may reflect increasing congestion and crime in inner cities and so on. The higher occupancy rate of the youngest age-classes may reflect the fact that they bear the brunt of economic downturns, with higher unemployment and low wage employment. Overall, the patterns of multiunit occupancy rates over time do not present a clear picture of the expected impact of economic cycles.

The Census Bureau [10] classifies as an urban area (2010 census definition) all densely developed areas of high population density, along with adjacent areas of nonresidential urban land uses including areas of low population density linking outlying densely settled areas with the densely settled core. An urban area must have a minimum population of 2500 , at least 1500 of which reside outside institutional accommodation. The 2010 census identified 3573 urban areas.

According to the Bureau of Economic Analysis, in year 1900 , approximately $60 \%$ of labor was employed by industry excluding agriculture (Figure 4). By 2010, the share of labor employed in agriculture was below $2 \%$, while the share of the services sector rose to $78 \%$. In $1900,39.6 \%$ of the population was residing in urban areas (Census Bureau [10]). By 2010 , the urban population had increased to $81 \%$. This rising trend in urbanization has received an impetus from the Great Recession. Based on Census Bureau estimates, Frey [9] reports that "between 2010 and 2015, the annual growth rates of cities with over half a million people were double the average annual rate between 2000 and 2010." After 2010, the combined populations of the largest cities grew at more

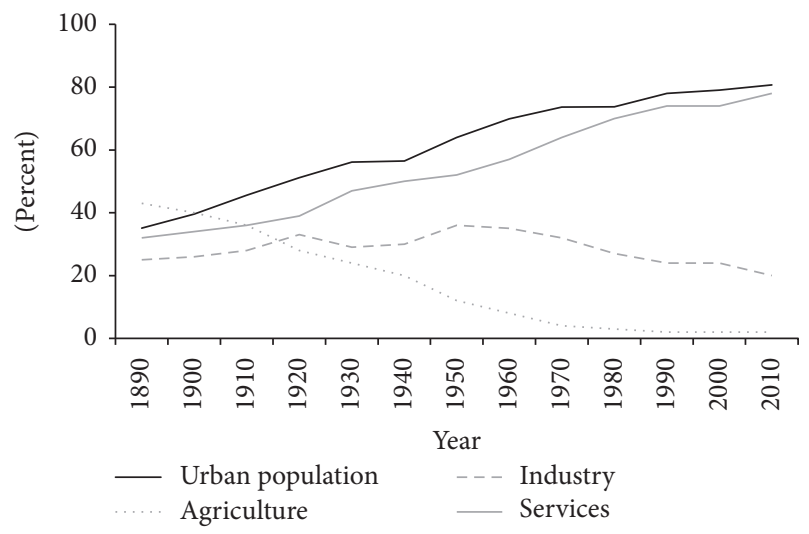

Figure 4: Urban population and sector-wise employment: 1890-2010 (source: Census Bureau [10] and Bureau of Economic Analysis).

than one percent a year, compared with only 0.5 percent, on average, during the 2000 to 2010 period.

Till World War I, the inner core of cities captured most of the population growth as migrant workers settled in rental housing near the sites of employment. In subsequent years, rapid growth in automobile ownership, rapid development of highways, and the introduction of long-term home mortgage loans, among other factors, changed the dynamics of urban growth in favor of suburbanization (Baum-Snow [29], Auch et al. [30]). Suburban growth has remained the main form of urban growth since. However, Frey [9] reports that after 2010 urbanization has witnessed a "reversal of the longstanding pattern of suburban growth outpacing city growth." The combined urban cores of major metropolitan areas grew at faster rates than their surrounding suburbs, counter to pre2010 trends.

Multiunit housing is primarily an urban housing option. According to the 1990 census, $97.39 \%$ of multiunit housing structures were reported in urban areas. Urban areas, as defined by the Census Bureau [10], include densely populated urban cores (including the city center or downtown and the Central Business District) as well as relatively sparsely populated suburban and other areas. Urban cores have traditionally accommodated the majority of demand for multiunit housing on account of higher population density. Brandt and Carmiel [31] report on the recent phenomenon of multiunit housing investments in the suburbs exceeding investment in urban cores in some regions.

As each succeeding cohort reaches the age of independent household formation, rising urbanization should increase demand for multiunit housing. However, in an urban landscape the demand for multiunit housing is determined by the rate of suburbanization. When the rate of migration to suburbs exceeds the rate of influx into urban cores, multiunit housing demand falls, and vice versa. For the better part of the past century the rate of suburbanization was higher (Hobbs and Stoops [32]). However, Glaeser and Saiz [11] and Moretti [12] describe the strong growth of select cities with highly educated populations since 1980. Similarly, Diamond [13] studies the growing concentration of young, college graduates 


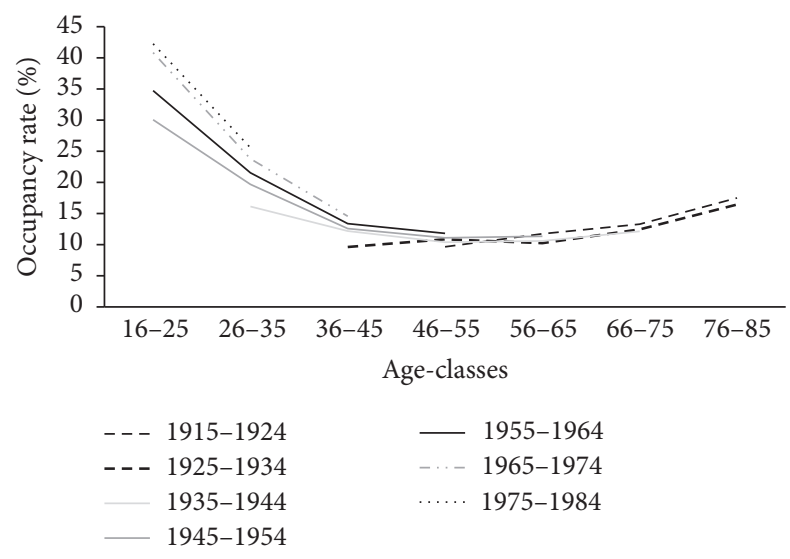

FIGURE 5: Rates of multiunit housing occupancy over age of householders: various birth cohorts (source: Ruggles et al. [24]).

in high wage, high rent cities from 1980 to 2000. Couture and Handbury [14] document the significant trend of young, college educated professionals settling in central business districts in select cities during the 2000 to 2010 period. Moretti [12] notes that cities that are hubs of technology and innovation are growing even while cities once dominated by traditional manufacturing are declining rapidly, losing jobs and residents. As a result of the intra-urban migration, multiunit housing stock in some regions suffers high vacancy rates even as other regions enjoy fast rising rents and new investments. Masnick [20] notes the significant gains to the population of cites in high growth regions from rising influx of foreign immigrants, mostly in the younger age-classes. The pattern of rising preference of recent cohorts for residing in urban cores should be reflected in increasing demand for multiunit housing.

Figure 5 plots multiunit occupancy rates for birth cohorts ranging from 1915-1924 to 1975-1984, as they age. While the younger age-classes of successive cohorts record a rising trend in occupancy rate, for most cohorts the trend reverses to a declining rate in the middle to senior age-classes. Recent birth cohorts (1975-1984, 1965-74, and 1955-1964) appear to be the exception to this occupancy rate reversal, though they are yet to reach their senior years. In general, the plots appear to support the expected trend of urbanization for recent cohorts.

\section{Data and Methodology}

To analyze the empirical impact of housing life cycle, economic cycles, and population growth in urban cores on multiunit housing demand, this study uses historical data on multiunit housing occupancy by age of householder (head of household/member of household in whose name the property was owned or rented) obtained from decennial census records from the Integrated Public Use Microdata Series (IPUMS) maintained by the University of Minnesota (Ruggles et al. [24]). Multiunit housing includes 5-9, 10-19, 20-49, and 50+ unit structures. Data from five censuses, from 1970 to 2010, is used. While housing occupancy data from the
1960 census is also available, it is unusable as a significant number of households are unclassified. Householders are grouped into seven age-classes of 10 years length, starting with the 16- to 25-year age-class and ending with the 76- to 85 -year age-class. Data on higher ages could not be included due to inconsistent reporting. The exclusion of ages higher than 85 years does not impact the analysis presented in this study. The five periods and seven age-classes yield eleven 10year birth cohorts ranging from 1885-1894 to 1985-1994.

The occupancy data was converted to occupancy rates. The total number of householders in each age-class in a census year constitutes the population that had the option of choosing multiunit housing, while the observed multiunit housing occupancy in each age-class per period constitutes the event. Thus, the occupancy rates represent event rates (event/population). Expressing the data as occupancy rates negates the impact of changing size of age-class population.

To analyze the data, we apply Age-Period-Cohort (APC) analysis. The impact of housing life cycle is reflected in change in multiunit housing occupancy rate over age of householders, called the age effect (A). The age effect assesses the consequences of growing older (Glenn [33]). The impact of economic cycles is reflected in occupancy rate changes over time and is a period effect $(\mathrm{P})$. Period effects refer to influences from social, cultural, and economic changes over periods in time that affect all age groups simultaneously, resulting in changes in attitudes, behaviors, health, emotional states, and economic preferences. The impact of rising preference for residing in urban cores is captured in changing occupancy rate over birth cohorts, called a cohort effect (C). Cohort effects capture formative experiences and influences that shape individual choices in different birth cohorts.

Equation (1) presents an Age-Period-Cohort accounting model for estimating A, P, and C effects (Mason et al. [34])

$$
\begin{aligned}
Y_{i j}=\mu+ & \beta_{i}+\gamma_{j}+\delta_{k}+\varepsilon_{i j} \\
& (i=1, \ldots, r ; j=1, \ldots, s ; k=1, \ldots, r+s-1),
\end{aligned}
$$

where $Y_{i j}=E_{i j} / P_{i j}$ is the event rate for the $i$ th age-class and $j$ th period with $E$ denoting the event or number of multiunit houses occupied by the $i$ th age-class in the $j$ th period and $P$ denoting the $i$ th age-class population in the $j$ th period. The effect of the $i$ th age-class is denoted by $\beta_{i}$, that of the $j$ th period by $\gamma_{j}$, and the $k$ th cohort by $\delta_{k}$. The mean of the dependent variable is represented by $\mu$ and $\varepsilon_{i j}$ denotes the random error. Dummy variables are used to represent age, period, and cohort effects.

The unique identification of $\mathrm{A}, \mathrm{P}$, and $\mathrm{C}$ effects from the linear regression model presented in (1) suffers from a collinearity problem. Specifically, since period (current year) equals cohort (birth year) plus age (years since birth), any of the three variables can be derived from a linear combination of the other two, resulting in perfect collinearity. Mason et al. [34] propose imposing one or more equality constraints on either of the three effects to solve the identification problem and obtain parameter estimates. However, the choice of constraint must rely on prior information, in the absence of which it is often arbitrary, with significant effect on the results, as demonstrated by Glenn [33]. 
Glenn [33] also discusses the Nakamura [35, 36] Bayesian method, and the Age-Period-Cohort Characteristic (APCC) method presented in O'Brien [37, 38]. The Nakamura Bayesian method is based on the assumption that successive parameters change gradually, which is not always true. The APCC method replaces the cohort with a cohort characteristic that is not highly correlated with cohort, such as the cohort size or another variable which varies by cohort. Period or age characteristics can also be used (called Age-Period Characteristic-Cohort model and Age Characteristic-PeriodCohort model, resp.). The limitation of the APCC is that the model yields unusable age and period coefficients. This is because age and period coefficients absorb the linear effects of cohort effects to the extent that the cohort characteristic does not account for it (O'Brien [38]). Thus, the APCC is useful only when the objective is limited to measuring the effect of the cohort characteristic.

A relatively new approach developed by Yang et al. [39], called the intrinsic estimator (IE) approach, has been shown to produce unbiased, efficient, and asymptotically consistent estimates (Yang et al. [40]) in simulations and has since been adopted by several studies (e.g., Schwadel [41], Miech and Koester [42], and Winkler and Warnke [43]). The IE is a principal components regression (PCR) estimator that circumvents the collinearity problem. The PCR removes the influence of the null space of the design matrix (matrix consisting of dummy variable column vectors for a reparametrized equation (1)) by estimating a constrained parameter vector that is a linear function of the parameter vector of the unconstrained equation (1) (Yang and Land [44]). The A, P, and C effect estimates are recovered by an inverse orthonormal transformation of the coefficient estimates of the PCR back to the original space of A, P, and C coordinates.

In this study, we use the intrinsic estimator approach to obtain estimates of $\mathrm{A}, \mathrm{P}$, and $\mathrm{C}$ effects. In order to isolate economic cycle effects from period effects, we apply the Age-Period Characteristic-Cohort approach using real Gross Domestic Product (GDP) annual growth rates for census years 1970 to 2010 (source: Federal Reserve Bank of St. Louis [6]) as the period characteristic.

\section{Results}

Before estimating the age, period, and cohort effects, it is important to estimate models with single effects (A, $\mathrm{P}$, and C) and double effects (AP, AC, and PC) to compare model fit statistics with the full APC model. A model fit test gives a sense of the relative contribution of individual effects and helps to choose the best model that summarizes the trends in the observed data (Yang and Land [44]). Table 1 reports Akaike Information Criteria (AIC) and Bayesian Information Criteria (BIC) statistics for the nested models. Selecting the model with the smallest statistic, it can be observed that the best model fit statistics are reported for the APC model. It can also be observed that the period effect appears to have the lowest contribution, alone or in combination with other effects.
TABLE 1: Model fit statistics.

\begin{tabular}{lcc}
\hline Model & AIC & BIC \\
\hline A & 180.49 & 191.38 \\
P & 265.61 & 273.38 \\
C & 245.61 & 262.72 \\
AP & 178.12 & 195.23 \\
AC & 137.37 & 163.81 \\
PC & 244.71 & 268.04 \\
APC & 3.03 & -39.82 \\
\hline
\end{tabular}

TABLE 2: Intrinsic estimator and APCC model estimated effect coefficients.

\begin{tabular}{|c|c|c|c|}
\hline & \multicolumn{2}{|c|}{ Coefficient estimates } \\
\hline & & $\begin{array}{l}\text { Intrinsic estimator } \\
\text { method }\end{array}$ & APCC method \\
\hline \multicolumn{2}{|l|}{ Intercept } & 19.25 & \\
\hline \multirow{7}{*}{ Age-class } & $16-25$ & 16.11 & \\
\hline & $26-35$ & 1.69 & \\
\hline & $36-45$ & -5.17 & \\
\hline & $46-55$ & -5.67 & \\
\hline & $56-65$ & -5.19 & \\
\hline & $66-75$ & -2.98 & \\
\hline & $76-85$ & 1.23 & \\
\hline \multirow{5}{*}{ Period } & 1970 & -1.18 & \\
\hline & 1980 & 1.06 & \\
\hline & 1990 & 0.89 & \\
\hline & 2000 & $0.20^{*}$ & \\
\hline & 2010 & -0.96 & \\
\hline \multirow{11}{*}{ Cohort } & $1885-1894$ & -3.16 & \\
\hline & 1895-1904 & $-0.04^{*}$ & \\
\hline & 1905-1914 & -1.35 & \\
\hline & $1915-1924$ & -3.29 & \\
\hline & $1925-1934$ & -3.76 & \\
\hline & 1935-1944 & -3.49 & \\
\hline & 1945-1954 & -2.64 & \\
\hline & 1955-1964 & $-0.90^{*}$ & \\
\hline & 1965-1974 & 2.91 & \\
\hline & 1975-1984 & 6.13 & \\
\hline & 1985-1994 & 9.59 & \\
\hline $\begin{array}{l}\text { Real } \\
\text { GDP }\end{array}$ & & & $-0.02^{*}$ \\
\hline
\end{tabular}

* denotes values not significantly different from zero at 5\% level of significance.

Table 2 lists the estimated effects using the intrinsic estimator approach. The effect coefficients are interpreted as deviations from the intercept or mean value. Thus, age-class $16-25$ increases the mean value of $19.25 \%$ by $16.11 \%$, period 1970 decreases it by $1.18 \%$, and cohort 1955-64 decreases it by $0.9 \%$. The table also lists the results of the Age-Period Characteristic-Cohort method, with real GDP serving as the period characteristic. As discussed previously, only the real 


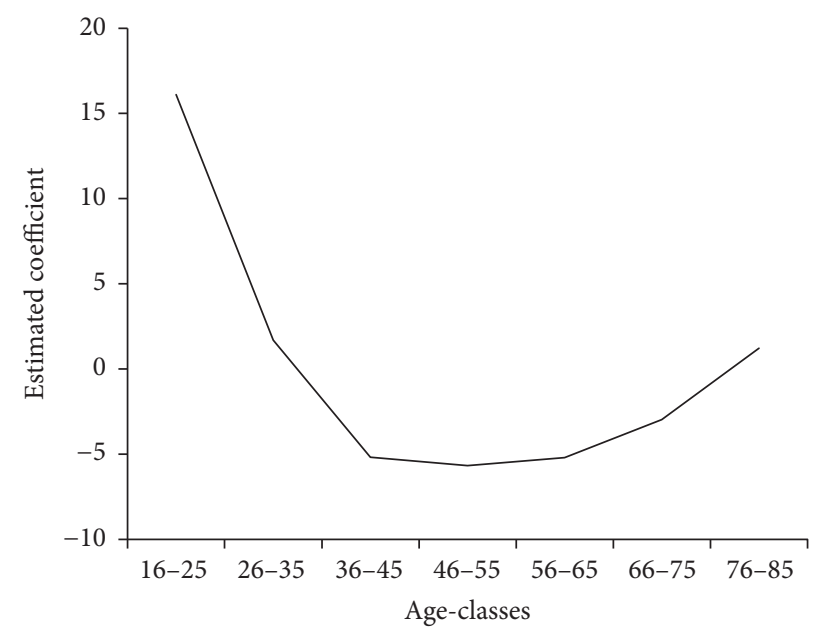

FIGURE 6: Estimated age effect coefficients.

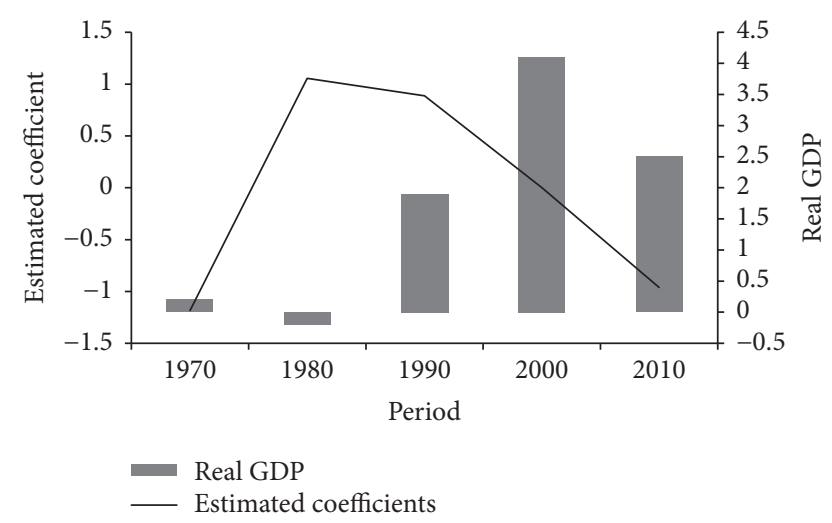

FIgURE 7: Estimated period effect coefficients.

GDP coefficient is interpretable. The unusable age and cohort effect coefficients from the APCC method are omitted in Table 2.

To aid interpretation, the estimated effect coefficients are plotted in Figures 6, 7, and 8. The patterns of estimated age effects coefficients plotted in Figure 6 confirm the housing life cycle theory. Multiunit occupancy rate is the highest in the lowest age-class (16-25). It falls sharply for the 26-35 and again for the 36-45 years age-class. After plateauing over the 36-45, 46-55, and 56-65 years age-classes, multiunit occupancy rate rises relatively modestly for the 66-75 years age-class and again for the 76-85 years age-class.

Estimated period effects coefficients are plotted in Figure 7 along with real GDP estimates for the census years. The pattern of estimated coefficients shows that multiunit occupancy rate was low in year 1970 and rose in 1980 and 1990 before falling again in years 2000 and 2010. As mentioned earlier, 1970, 1980, and 1990 were years with recessions, while years 2000 and 2010 were years of economic growth. With the exception of 1970, the pattern of estimated coefficients appears broadly consistent with the expected negative relationship between economic conditions and multiunit housing. As discussed earlier, the existence of multiple

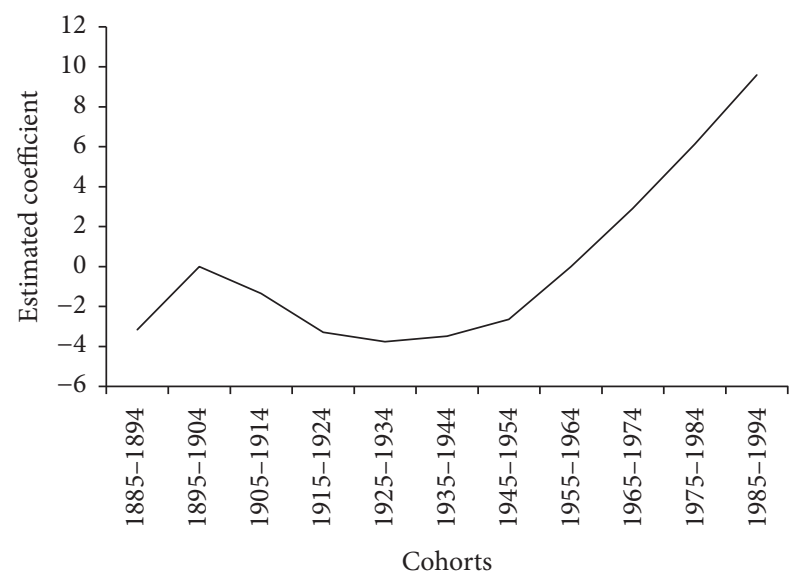

FIGURE 8: Estimated cohort effect coefficients.

social, economic, and demographic changes over time make it necessary to isolate the impact of economic cycles from total period effects. To isolate the impact of economic conditions, we apply the APCC method. The result of the APCC method confirms a weak negative relationship, with an estimated real GDP coefficient value of -0.02 that is not significantly different from zero at the $5 \%$ level of significance.

Figure 8 plots the estimated cohort effects coefficients. Multiunit housing occupancy rate is relatively unchanged for cohorts 1885-1894 through 1955-1964 before it rises sharply for the 1965-1974 cohort and continues rising for subsequent cohorts. This pattern suggests that the impact of urbanization on demand for multiunit housing started with Generation X reaching their independent household formation age in the 1980s. The continuing sharp rise in cohort effects suggests that the succeeding Millennials generation is contributing to a strong growth in population in urban cores. It must be noted that the Baby Boomers and succeeding generations had not reached their senior years by year 2010. As a consequence, their cohort effect coefficients capture multiunit occupancy rates in their working-age years only.

A limitation of the linear APC analysis is that it produces constant coefficient estimates for a dynamic process of housing choice evolution. For example, Gyourko and Linneman $[45,46]$, critical of the housing life cycle model, argues that the impact of marital status and family structure on tenure choice has weakened, while that of education and income has grown. This limitation restricts the utility of the results for forecasting future housing trends.

\section{Conclusions}

It is argued that the entry of the Baby Boomers generation into senior ages, weak economic conditions, and rising trend of population growth in urban cores are responsible for the significant growth in multiunit housing starts since the end of the Great Recession in 2009. We examine empirical evidence for the impact of these three explanatory factors on multiunit housing occupancy rates from 1970 to 2010, applying AgePeriod-Cohort analysis. 
The housing life cycle theory supports the argument for growth in multiunit housing demand resulting from the aging of the Baby Boomers generation into senior years. According to the theory, demand for multiunit housing should be highest from the youngest and senior age-classes, based on their family size, income, occupational mobility, and so forth. Estimated coefficients for age effects support this theory. Contribution to occupancy rates are the highest by the youngest age-classes, plateau in the middle age-classes, before registering a modest increase for the senior age-classes. On the basis of these results the growth in multiunit housing starts after the Great Recession could be attributed to the anticipated rise in demand from Baby Boomers passing into the senior years.

Economic cycles may affect demand for multiunit housing through their impact on wealth, incomes, and employment. When incomes and employment opportunities are low, demand for multiunit housing is expected to grow and vice versa. An APCC analysis provides evidence of a weak negative relationship, which may be explained by the sticky nature of housing decisions. The average duration of recessions during the period analyzed is about one year. It is likely that the housing investment decisions of existing and potential house owners are not significantly impacted by the short duration of recessions. However, the Great Recession may be an exception since it was longer (18-month duration) and followed by an unprecedented weak recovery stretching over years. More significantly, the Great Recession was preceded by the bursting of a bubble in the housing market. Vast numbers of house owners that lost their homes to foreclosure may have been forced into the rental market. Nevertheless, given the transient nature of economic cycles it is unlikely that they have more than a marginal impact on housing starts, which are forward looking by nature, with a longer investment horizon than the duration of a typical recession.

Demand for multiunit housing grows when rising proportions of cohorts prefer to settle in densely populated urban cores. Estimated coefficients for cohort effects show increasing demand for multiunit housing starting with Generation $\mathrm{X}$ (entering the housing market from 1980s onwards). This finding is consistent with observations in Glaeser and Saiz [11], Moretti [12], Diamond [13], and Couture and Handbury [14] on the trend of young, college educated professionals settling in urban centers of select cities since the 1980s, contributing to high growth rates of the cities. The results also show that demand from the succeeding Millennials generation has increased sharply. The estimated cohort effect coefficients support the argument that the growth in multiunit housing starts after the Great Recession could be the result of strong growth of population in urban cores.

Over all, results of the analysis suggest that the strong growth in multiunit housing starts after the Great Recession has been fueled by expectations of rising demand from Baby Boomers reaching their senior years and recent cohorts drawn to urban cores.

The Census Bureau [10] projects a $23 \%$ increase in population over the three decades from 2010: from 308 million to 380 million by 2040 . The increase in population is

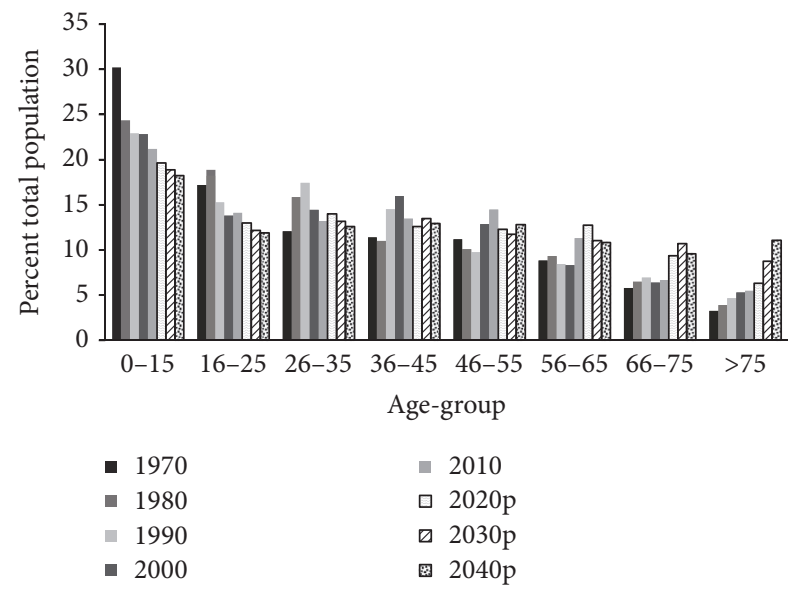

FIGURE 9: Population distribution by age-class, with projections: 1970-2040 (source: Census Bureau [10] 2014 Projection) (note: suffix "p" denotes projected).

projected to be accompanied with a significant change in age distribution of the population. The percentage of population aged between 16 and 35 years is projected to fall from $27 \%$ to $25 \%$, while that of those over 65 years will rise from $12 \%$ to $21 \%$. In absolute numbers, the $16-35$-year-old population will change from 84 million to 93 million, while the over 65 years old will increase from 38 million to 79 million. Aging of the Baby Boomers generation will be a significant contributor to this aging of the population, as can be observed from Figure 9.

Utilizing detailed information on composition of the projected population provided by the Census Bureau, Rappaport [47] predicts that multiunit housing starts will peak at about 570,000 annual units by year 2019 and settle to an annual rate of about 400,000 units in the following decade. In 2016, multiunit starts were 380,800 annual units. Rappaport [47] bases the predicted rise in multiunit starts primarily on the expected inflation in the numbers of senior population, as Baby Boomers age.

Based on results of empirical analysis presented in this study, growth in demand for multiunit housing as a result of the expected doubling of the senior population over the next three decades will be largely offset by meager increase in the population of 16-35 year olds. From Figure 2, it can be observed that the 16-25-year age-class has a three times higher occupancy rate in comparison to the senior ageclasses, while the 26-35-year age-class has a two times higher occupancy rate. The rate of growth of population in urban cores can also be expected to slow down as the population ages, moderating demand for multiunit housing over the long-term.

In the short to medium term, multiunit housing investments may be supported at elevated levels by demand from younger age-classes and retiring Baby Boomers. Myers [48] contends that Millennials presently congregating in urban cores will start migrating to suburbs by 2020 as the cohort ages past age 25 and economic and housing market conditions change. However, the migrating Millennials will be replaced by the succeeding Generation Z (1998-). The results of 
the analysis in this study show that the multiunit housing occupancy rate of the succeeding generation can be expected to be higher than the generation it replaces. In addition, the occupancy rate of Millennials could remain higher, compared to previous generations, throughout their housing life cycle. Retiring Baby Boomers will continue adding to demand as they reach the senior years. Intra-urban population movement, as observed by Moretti [12] and Frey [9], can also be expected to contribute to demand in the short term.

\section{Conflicts of Interest}

The authors declare that they have no conflicts of interest.

\section{References}

[1] J. Rappaport, "Millennials, baby boomers, and rebounding multifamily home construction," SSRN Electronic Journal.

[2] W. A. V. Clark and F. M. Dieleman, Households and Housing: Choice and Outcomes in the Housing Market, Center for Urban Policy Research, Rutgers University, New Brunswick, NJ, USA, 1996.

[3] L. D. Jones, "The tenure transition decision for elderly homeowners," Journal of Urban Economics, vol. 41, no. 2, pp. 243-263, 1997.

[4] P. G. VanderHart, "The housing decisions of older households: a dynamic analysis," Journal of Housing Economics, vol. 7, no. 1, pp. 21-48, 1998.

[5] D. Myers and S. H. Ryu, "Aging baby boomers and the generational housing bubble: Foresight and mitigation of an epic transition," Journal of the American Planning Association, vol. 74, no. 1, pp. 17-33, 2008.

[6] Federal Reserve Bank of St. Louis, Federal Reserve Economic Data (FRED), https://alfred.stlouisfed.org.

[7] Bureau of Labor Statistics, U.S. Bureau of Labor Statistics, https://www.bls.gov/.

[8] National Association of Home Builders, "Housing Opportunity Index (HOI)," http://www.nahb.org/en/research/housingeconomics/housing-indexes/housing-opportunity-index.aspx.

[9] W. H. Frey, "Mid-decade, big-city growth continues," Brookings Institution, 2016, https://www.brookings.edu/blog/the-avenue/ 2016/05/23/mid-decade-big-city-growth-continues/.

[10] Census Bureau, U.S. Census Bureau, https://www.census.gov/.

[11] E. L. Glaeser and A. Saiz, "The rise of the skilled city," BrookingsWharton Papers on Urban Affairs, vol. 2004, no. 1, pp. 47-105, 2004.

[12] E. Moretti, The New Geography of Jobs, Houghton Mifflin Harcourt Publishing Co, New York, NY, USA, 2012.

[13] R. Diamond, "The determinants and welfare implications of US Workers' diverging location choices by skill: 1980-2000," American Economic Review, vol. 106, no. 3, pp. 479-524, 2016.

[14] V. Couture and J. Handbury, Urban Revival in America, 2000 to 2010, Working Paper, University of Pennsylvania, 2015.

[15] G. D. Jud, J. D. Benjamin, and G. S. Sirmans, "What do we know about apartments and their markets?" The Journal of Real Estate Research, vol. 11, no. 3, pp. 243-257, 1996.

[16] E. N. Zietz, "Multifamily housing: a review of theory and evidence," Journal of Real Estate Research, vol. 25, no. 2, pp. 185244, 2003.
[17] V. Zarnowitz, Business Cycles: Theory, History, Indicators and Forecasting, National Bureau of Economic Research, New York, NY, USA, 1992.

[18] N. G. Mankiw and D. N. Weil, "The baby boom, the baby bust, and the housing market," Regional Science and Urban Economics, vol. 19, no. 2, pp. 235-258, 1989.

[19] B. W. Hamilton, "The baby boom, the baby bust, and the housing market. A second look," Regional Science and Urban Economics, vol. 21, no. 4, pp. 547-552, 1991.

[20] G. S. Masnick, “The new demographics of housing," Housing Policy Debate, vol. 13, no. 2, Article ID 9521444, pp. 275-321, 2002.

[21] J. B. Lansing and L. Kish, "Family life cycle as an independent variable," American Sociological Review, vol. 22, no. 5, pp. 512519, 1957.

[22] K. F. McCarthy, "The household life cycle and housing choices," Papers of the Regional Science Association, vol. 37, no. 1, pp. 5580, 1976.

[23] J. Pitkin and G. Masnick, "Projections of Housing Consumption in the U.S., 1980 to 2000, By a Cohort Method," in Annual Housing Survey Studies, vol. 9, p. 124, US Department of Housing and Urban Development, 1980.

[24] S. Ruggles, K. Genadek, R. Goeken, J. Grover, and M. Sobek, Integrated Public Use Microdata Series: Version 6.0 [Machinereadable database], University of Minnesota, Minneapolis, 2015.

[25] R. M. Kreider and R. Ellis, "Number, timing and duration of marriages and divorces: 2009," 24 pages, U.S. Census Bureau, 2011.

[26] M. T. Katzman, "The contribution of crime to urban decline," Urban Studies, vol. 17, no. 3, pp. 277-286, 1980.

[27] W. H. Frey, "White flight: racial and non-racial causes," American Sociological Review, vol. 44, no. 3, pp. 425-448, 1979.

[28] The National Bureau of Economic Research, http://www.nber .org.

[29] N. Baum-Snow, "Did highways cause suburbanization?” Quarterly Journal of Economics, vol. 122, no. 2, pp. 775-805, 2007.

[30] R. Auch, J. Taylor, and W. Acevedo, "Urban Growth in American Cities: Glimpses of U.S. Urbanization," in U.S. Geological Survey, p. 52, U.S. Department of the Interior, 2004.

[31] N. Brandt and O. Carmiel, "Apartment Investors Turn to Suburbs after Crowding Cities," Bloomberg, 2015, https://www .bloomberg.com.

[32] F. Hobbs and N. Stoops, "Demographic Trends in the 20th Century," in Census 2000 Special Reports, Series CENSR-4, p. 220, U.S. Census Bureau, 2002.

[33] N. D. Glenn, Cohort Analysis, Sage Publications, Inc., California, CA, USA, 2nd edition, 2005.

[34] K. O. Mason, W. M. Mason, H. H. Winsborough, and W. K. Poole, "Some methodological issues in cohort analysis of archival data," American Sociological Review, vol. 38, no. 2, pp. 242-258, 1973.

[35] T. Nakamura, "Bayesian cohort models for general cohort table analyses," in Proceedings of the Institute of Statistical Mathematics, vol. 29, pp. 77-97, Institute of Statistical Mathematics.

[36] T. Nakamura, "Bayesian cohort models for general cohort table analyses," Annals of the Institute of Statistical Mathematics, vol. 38, no. 1, pp. 353-370, 1986.

[37] R. M. O’Brien, "Relative cohort size and age-specific crime rates: an age-period-relative-cohort-size model," Criminology, vol. 27, no. 1, pp. 57-78, 1989. 
[38] R. M. O’Brien, “Age period cohort characteristic models," Social Science Research, vol. 29, no. 1, pp. 123-139, 2000.

[39] Y. Yang, W. J. Fu, and K. C. Land, "A methodological comparison of age-period-cohort models: the intrinsic estimator and conventional generalized linear models," Sociological Methodology, vol. 34, no. 1, pp. 75-110, 2004.

[40] Y. Yang, S. Schulhofer-Wohl, W. J. Fu, and K. C. Land, "The intrinsic estimator for age-period-cohort analysis: what it is and how to use it," American Journal of Sociology, vol. 113, no. 6, pp. 1697-1736, 2008.

[41] P. Schwadel, "Age, period, and cohort effects on religious activities and beliefs," Social Science Research, vol. 40, no. 1, pp. 181-192, 2011.

[42] R. Miech and S. Koester, "Trends in U.S., past-year marijuana use from 1985 to 2009: an age-period-cohort analysis," Drug and Alcohol Dependence, vol. 124, no. 3, pp. 259-267, 2012.

[43] R. Winkler and K. Warnke, "The future of hunting: an ageperiod-cohort analysis of deer hunter decline," Population and Environment, vol. 34, no. 4, pp. 460-480, 2013.

[44] Y. Yang and K. C. Land, Age-Period-Cohort Analysis: New Models, Methods, and Empirical Applications, Chapman \& Hall/ CRC Interdisciplinary Statistics Series, CRC Press, Boca Raton, FL, USA, 2013.

[45] J. Gyourko and P. Linneman, "Analysis of the changing influences on traditional households' ownership patterns," Journal of Urban Economics, vol. 39, no. 3, pp. 318-341, 1996.

[46] J. Gyourko and P. Linneman, "The changing influences of education, income, family structure and race on homeownership by age over time," Journal of Housing Research, vol. 8, pp. 1-26, 1997.

[47] J. Rappaport, "The demographic transition from single-family to multifamily housing," Economic Review, vol. 98, no. 4, pp. 29$58,2013$.

[48] D. Myers, "Peak millennials: three reinforcing cycles that amplify the rise and fall of urban concentration by millennials," Housing Policy Debate, vol. 26, no. 6, pp. 928-947, 2016. 


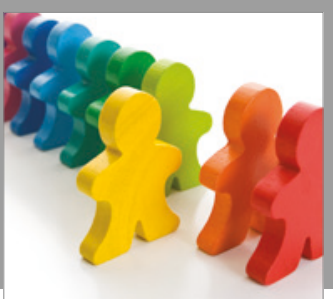

Autism

Research and Treatment
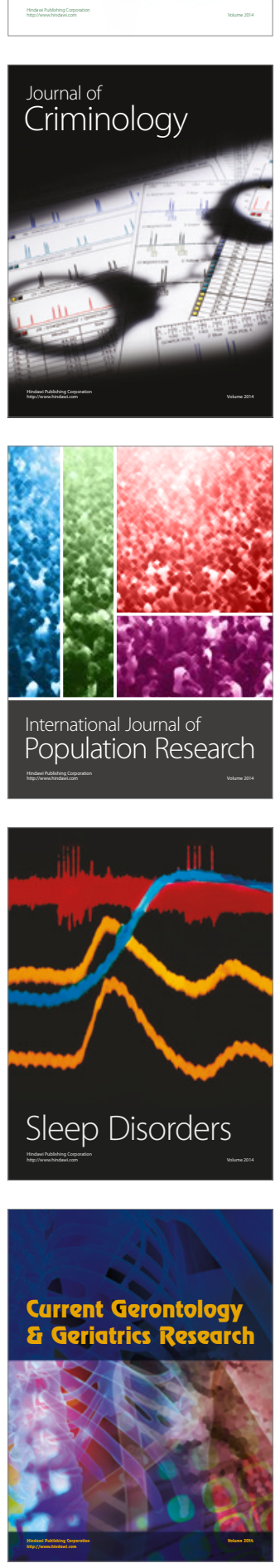

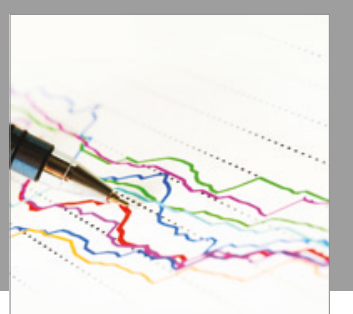

Economics

Research International

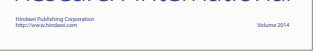

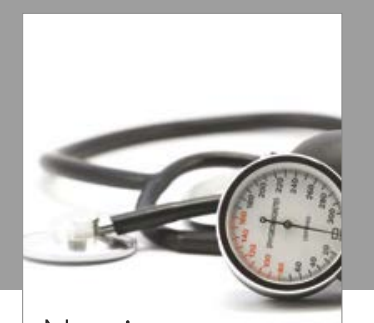

Nursing

Research and Practice

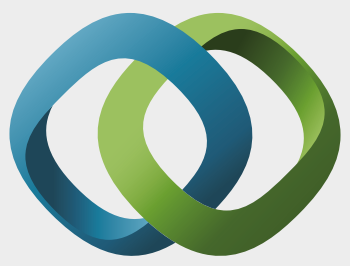

\section{Hindawi}

Submit your manuscripts at

https://www.hindawi.com
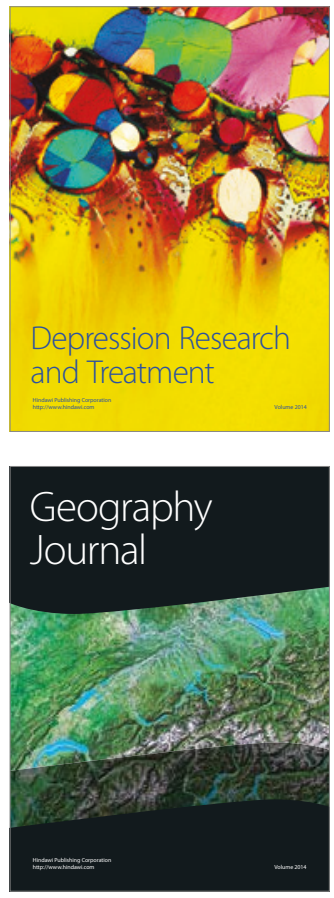
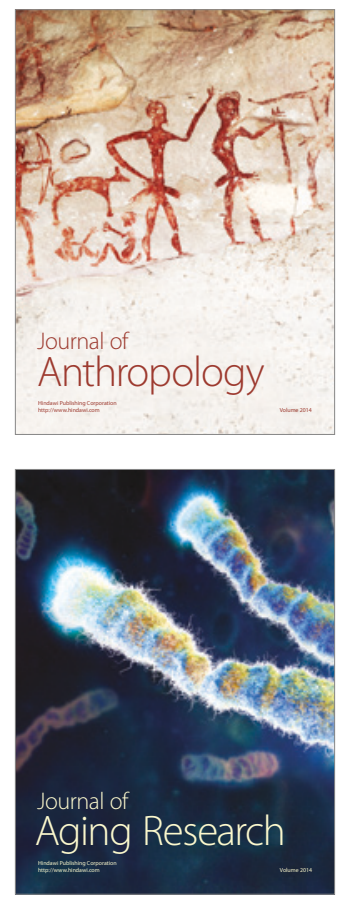
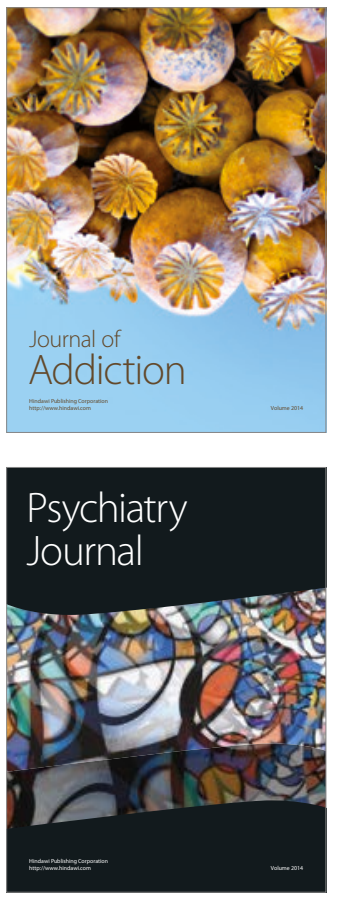

Child Development

Research

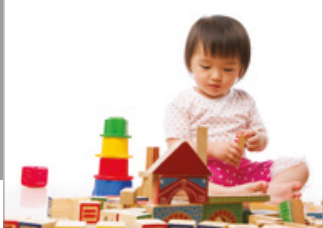

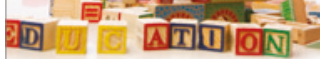
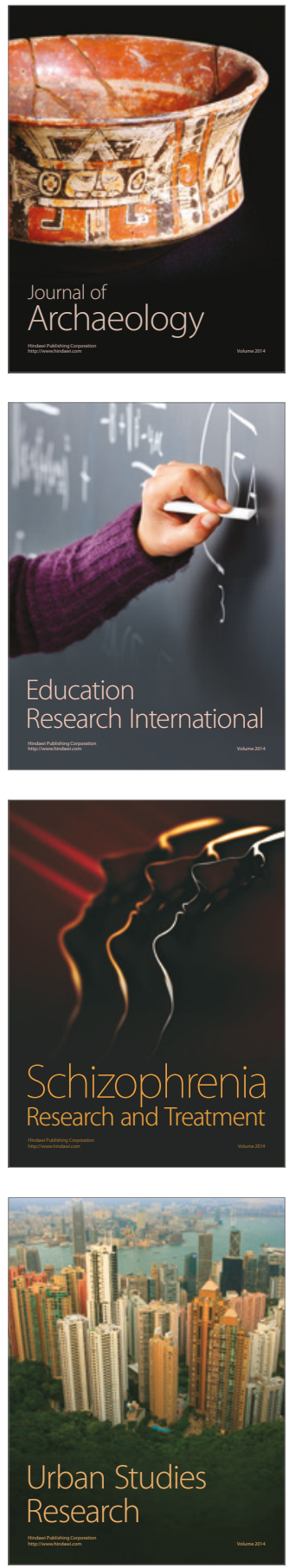